\title{
PROPUESTA PARA INICIAR UN PROCESO DE CAMBIO ORGANIZACIONAL MODELO GAT
}

YOLANDA BUSTAMANTE SÁNCHEZ*

E-mail: ybustamante@unmsm.edu.pe

\begin{abstract}
RESUMEN
La autora propone el Modelo G.A.T. como el más adecuado para iniciar un proceso de cambio en la organización y enfrentar los tiempos actuales, en donde el acertado manejo de los recursos humanos redunda en beneficio de la institución.

Palabras claves: Capacitación, aprendizaje colaborativo organizativo, manejo del tiempo.
\end{abstract}

\begin{abstract}
The author proposes the G.A.T. Model so as to begin a change process in the organization and face the present time where the appropriate management of the human resources will be redundant on the promotion and benefit of the institutution.
\end{abstract}

Keywords: Training organizational collaborative learning, handling of time.

Estamos insertos en una época de cambio en donde se están implantando nuevos conceptos en los diversos campos del saber, donde las Tecnologías de la Información y Comunicación contribuyen decididamente.

En este contexto, las organizaciones deben considerar los recursos humanos como los gestores de cambios profundos y decisivos en la institución; por tanto se ha de fortalecer el talento humano, su capacidad creativa, promover las habilidades directivas con dominio de herramientas diversificadas y actualizadas a fin de resolver problemas, manejar la incertidumbre y hacer frente a los mercados actuales y futuros escenarios laborales.
Se propone el Modelo G.A.T que es la gestión del talento humano a través de un plan de capacitación, el aprendizaje colaborativo organizativo que implica el manejo de grupos humanos acertadamente, desarrollando sus aptitudes comunicativas y brindándoles un acertado manejo del tiempo a fin de lograr los objetivos institucionales.

\section{OBJETIVOS}

Promover un Programa Interno de Capacitación a fin de mejorar el desempeño, promover el aprendizaje colectivo organizativo, con el manejo acertado del tiempo.

* Licenciada en Educación. Coordinadora del Programa de Idiomas Extranjeros de la Escuela de Postgrado (UNMSM). Profesora de la Facultad de Ciencias Administrativas de la UNMSM. 
- Gerenciar el talento humano, y promover la creatividad, trabajo en equipo, liderazgo.

- Conducir a la mejora personal y profesional.

- Mejorar la aptitudes comunicativas.

- Mejorar conocimientos.

- Fomentar oportunidades de estudio y de reunión con colegas.

- Mejorar el nivel de satisfacción con el puesto.

- Permitir el logro de metas individuales.

- Promover la investigación y aprendizaje continuo.

- Contribuir a la mejora institucional.

\section{CAPACITACIÓN}

A mediado de los años 50, la mitad de las compañías importantes contaban con algún tipo de programa de capacitación. A finales de los 70 , el $75 \%$ de las compañías importantes tenían departmentos independientes dedicados exclusivamente a ofrecer una completa gama de programas de capacitación ${ }^{1}$.

La capacitación es un medio eficaz para hacer productivas a las personas y facilita el aprendizaje de comportamientos relacionado con el trabajo, su eficacia se ha comprobado en más del $80 \%$ de todos los programas de capacitación. Hay muchas formas de impartir capacitación, desde sugerir lecturas hasta talleres vivenciales, pero su principal objetivo es proporcionar conocimientos en los aspectos técnicos del trabajo. Según Grados²:

"La capacitación es la acción destinada a incrementar las aptitudes y los conocimientos del trabajador con el propósito de prepararlo para desempeñar eficientemente una unidad de trabajo específico y personal».

El término desarrollo a diferencia de capacitación, tiene mayor amplitud y profundidad. Significa el progreso integral del hombre y consiguientemente, abarca la adquisición de conocimientos, el fortalecimiento de la voluntad, la disciplina del carácter y la adquisisición de todas las habilidades que son requeridas para el desarrollo de los ejecutivos ${ }^{3}$. Es una capacitación a largo plazo, su objetivo es desarrollar al empleado para algún puesto futuro ${ }^{4}$.

Es importante tener en cuenta que el número y variedad de programas de capacitación es muy grande en una empresa de gran enver- gadura, al igual que su duración: pueden ser horas, días, meses o años. El tipo de capacitación que se adoptará en una organización dependerá del tamaño de la empresa, de las facilidades para el desarrollo del programa y de lo que se quiera enseñar específicamente.

\section{CAPACITACIÓN CONTINUA}

Hoy en día este término va cobrando más fuerza pues se requiere estar al tanto de los últimos conocimientos, lo que se hace difícil para muchos debido a diversos factores (económicos, personales, sociales).

Para adaptarse al cambio es necesario considerar que éste es un proceso permanente, para lo cual tanto individuos como organizacioes deben establecer claras visiones de futuro que les permitan efectuar adecuados diagnósticos del presente y así realizar transiciones planificadas hacia nuevos niveles de desarrollo y excelencia. Para tal fin, tanto los modelos basados en la conducta como aquellos basados en el diseño pueden de ser de gran ayuda en tanto sea posible integrarlos en un solo sistema que a continuación se propone.

\section{APRENDIZAJE COLECTIVO ORGANIZATIVO}

Enfoque de aprendizaje que implica una modificación del comportamiento de quienes dirigen y operan la organización. El aprendizaje será de TRIPLE CICLO:

- Es preciso que el comportamiento organizacional evolucione de la simple aceptación de las normas.

\section{- El entendimiento de dichas normas.}

- Superar los diversos niveles de mejoramiento, renovación y desarrollo.

Este enfoque integra, concilia y relaciona los conceptos de personalidad, actitudes y conducta, proyectándolos hacia la realidad organizacional.

Esta vía tiene un doble sentido porque el individuo es capaz de aprender y en el transcurso de tiempo modificará a algunas características de su personalidad.

Proyectando la dinámica de personalidad, actitudes y conducta a la organización, nos encontramos con elementos en la organización que corresponden a la cultura, estructura y campo organizacional (cultura organizacional). 
El entorno en que operan las empresan es cada vez más complejo, dinámico y con un mayor nivel de incertidumbre. El Aprendizaje Colaborativo Organizativo resulta de gran importancia para poder afrontar estos retos, puesto que permite a las empresas mantener un cambio sostenido.

El aprendizaje se considera en sentido unidireccional, en el que los procesos cognitivos inciden sobre la acción pero no al contrario.

La estructura global del modelo se puede dividir en dos partes:

- Los factores condicionantes del aprendizaje, conforme a su naturaleza, se pueden agrupar en tres bloques: compromiso con la visión de una organización de aprendizaje; acciones y dispositivos que impulsan el aprendizaje en todos los niveles de la organización; y perfil de la organización, ya que existen varios elementos de gestión que pueden condicionar el comportamiento organizativo.

Se puede argumentar que el aprendizaje organizativo es un proceso idiosincrásico, por lo que cada organización tiene un perfil distinto en base a las características que definen sus elementos de gestión tales como liderazgo, estructura, estrategia, gestión de personas, sistemas de información, comunicación y cultura.

- Los Resultados del Aprendizaje han de producir la mejora del comportamiento organizativo, es decir que la organización puede cambiar de forma continua, adaptándose al entorno, generando nuevas oportunidades de mercado, siendo más competentes, desarrollo de los sujetos de la organización pues estos están inmersos en un proceso de aprendizaje continuo.

\section{Gestionando el talento humano a través del trabajo en equipo}

Un equipo exitoso es aquel donde no existen las individualidades, porque a sus miembros los une la pasión y vocación de servicio. Se entrenan conjuntamente, soportanto las peores presiones con mucho positivismo.

Para tal fin se necesita que los equipos tengan la oportunidad de acoplarse a través de un entrenamiento intenso. Ello implica un proceso colectivo, no lo puede realizar una sola persona.
Cuando varios individuos se reúnen para formar un grupo, cada cual aporta sus conocimientos personales, habilidades, ideales y motivaciones. A veces la propia naturaleza humana es el principal problema a superar. Grupo y equipo son dos términos que difieren, así, grupo es la reunión de personas con cierto interés común. El equipo es el conjunto de personas motivadas hacia objetivos perfectamente definidos, donde cada miembro aporta con lo mejor para lograr el objetivo común.

\section{Ciclo vital de formación del equipo}

En su obra «Estudios de Grupos y Organizaciones», B.W. Tuckman y M.A.C. Jenson proponen un modelo de ciclo vital que consta de las siguientes fases:

\section{a. Formación}

Etapa que se caracteriza por la importancia que los miembros del equipo atribuyen a su comportamiento pasado. Los integrantes no están seguros de la razón por la que forman parte del equipo; esperan que el líder los oriente. La producción es poca en esta etapa de desarrollo.

El líder incluye actividades tales como aclaración y dirección, creación de un clima positivo y de oportunidad de triunfar pronto, buscando resultados rápidos y directos.

\section{b. Turbulencia}

Durante esta etapa, el conflicto y la competencia salen a relucir en el equipo. Algunos integrantes suelen ser hostiles o asumen una actitud defensiva. El conflicto resulta de los intentos de algunos miembros de dominar el grupo.

Para salir de esta fase de turbulencia el equipo tiene que adoptar una mentalidad de resolución de problemas. La producción sigue siendo poca. El líder trata de negociar, busca el consenso; hace las veces de instructor, maestro y mentor.

\section{c. Establecimiento de normas}

En esta etapa el equipo se integra. Sus integrantes convienen en sus metas y objetivos, se identifican plenamente con ellos. Esta fase 
se caracteriza por el reconocimiento de las aportaciones de los distintos miembros, hay cohesión, un compartir de sentimientos e impresiones, un clima cómodo y seguro. El líder ayuda a crear confianza y buenas relaciones de trabajo y alienta al equipo haciendo las veces de mentor o asesor.

\section{d. Rendimiento}

A estas alturas la identidad del equipo está bien perfilada y el espíritu de sus integrantes es fuerte. Se interesan tanto en sus tareas como en el elemento humano de éstas. Los equipos llegan a su mayor capacidad, caracterizándo se por la intensidad de sus relaciones interpersonales. El líder los inspira para que alcancen mayores niveles de productividad.

\section{e. Disolución}

Una vez alcanzada la meta el equipo reconoce sus propios triunfos, acepta las recompensas pero se desintegra hacia una nueva oportunidad. Si el líder no logra conseguir nuevos objetivos, metas que cumplir, entonces el equipo se diluye.

\section{La magia de la sinergia}

Esta se da cuando los miembros del equipo trabajan en armonía y se ayudan entre sí, reconociendo los puntos fuertes y los débiles de cada uno y complementando su esfuerzo, además de compartir la convicción de su responsabilidad recíproca.

\section{Requerimientos para un efectivo aprendizaje colaborativo organizativo}

Este término implica un acertado manejo de grupos lo cual se logrará a través de:

- Fomentar la colaboración grupal generando grupos participativos.

- Crear un clima de confianza desarrollando las competencias de los participantes.

- Facilitar una interdependencia positiva.

- Reconocer el aporte de los individuos y su esfuerzo, prestando atención a sus comentarios.

- Celebrar sus éxitos.
- Aceptar las diferencias entre las personas, manejando las situaciones críticas de manera positiva.

- Delegar responsabilidades.

- Motivar la lluvia de ideas y grupos de discusión saludable.

\section{Manejo del tiempo}

A fin de optimizar el flujo de trabajo se precisa manejar el tiempo acertadamente, lo cual se consigue a través del uso del software y bases de datos, herramientas integradoras de gestión estratégica, entre otras tecnologías de información y comunicación.

Para este fin se requiere concentrar la atención en una meta específica, priorizando las actividades, estableciendo plazos precisos, no dejando para mañana lo que se puede hacer hoy, tomando decisiones rápidas.

Si se está en un rol gerencial, se han de delegar responsabilidades, lo que implica tener suficiente confianza y una actitud positiva. Esto maximizará la efectividad en las actividades desplegadas.

También es necesario practicar la puntualidad que no sólo mejora la autoconfianza sino que crea una impresión favorable y manejar un rol de visitas, entrevistas y/o reuniones en una agenda. También se puede practicar el plan PAD, que consiste en planificar el día, actuando en el momento preciso y tomando descanso a fin de recuperar energía y emprender acciones futuras.

Un sistema de archivo efectivo permite optimizar tiempos: hay un lugar para cada cosa y cada cosa tiene su lugar.

En cuanto al aspecto personal es necesario estimular el cerebro mediante la lectura rápida. También se pueden ejercitar los ojos en la práctica de aumentar el campo visual, lo que mejorará la comprensión lectora del capacitado. Finalmente, al momento de planificar el tiempo es necesario incluir un horario especial para el desarrollo físico.

\footnotetext{
NOTAS

${ }^{1}$ Campbell, 1971.

${ }^{2}$ Grados, 1999.

${ }^{3}$ Siliceo, 1973.

${ }^{4}$ Dissler, 1994.
} 


\section{BIBLIOGRAFÍA}

Ceserani Jonne. Big Ideas. Kogan Page, London and Sterling, 2003, 195.

Geoff Smith. Leading the Professionals. Kogan Page Ltd. London USA, 2004, 241.

Richard Pettinger. Mastering Management Skills. Palgrave, Great Britain, 2001, 262.

Kouzes James, Posner Barry. Leadership Challenge. Jossey-Bass, San Francisco, CA, 2002, 399.

Williams, Michael. The War for Talent. Cipd, London, 2000, 251.
Tosi, Henry and Mero Neal. The Fundamentals of Organizational Behavior. Blackwell Publishing. USA, 2003, 301.

Lipman-Blumen Jean and Leavitt Harold. Hot Groups. Oxford Univesity Press, USA, 1999, 282.

Kamp, di. The 21st century manager. Kogan Page, UK, USA, 1999, 210.

Firestone Joseph and McElroy Mark. Key Issues in the new knowledge Management. Butterworth Heinemann, USA, 2003, 353. 
